\title{
University Quality-oriented Education Research: Present Situation and Prospect
}

\author{
Wang Mingming \\ School of Shandong Xiehe University \\ JiNan250109, China \\ 476398949@qq.com
}

\begin{abstract}
The main purpose of this paper is to explore the current situation and development trend of university Qualityoriented education. Adopts the method of literature and comprehensive analysis. Through the academic library and the relevant literature collected by the provincial library, this paper discusses the current situation and development trend of university Quality-oriented education. After the research, the scholars paid more attention to the university Quality-oriented education research, and thought that the implementation of it was the strategic theme of the reform and development in the new period. The study of the meaning of college Quality-oriented education, the relationship with other factors, and the research on the practice of all colleges and universities will help to promote the implementation of Quality-oriented education in universities.
\end{abstract}

Keywords-Universities; Quality-oriented education; general education; curriculum reform; Promotion approach

\section{INTRODUCTION}

With the continuous deepening and development of theoretical research and practical exploration of higher education in our country, the research on Quality-oriented education in universities has gradually deepened, and the understanding of connotation and denotation has been enriched and perfected. Take the university Quality-oriented education as the key word, search in CNKI, and comb and comment on 277 articles of Chinese core periodicals and CSSCI periodicals from 1995 to 2017, and summarize and analyze them as the research results of 8 subjects: Research on the meaning of University Quality-oriented Education, Study on the responsibility of University Quality-oriented Education, Research on the relationship between Quality-oriented education and general education in Universities, Research on University Quality-oriented Education and educational reform University Quality-oriented Education and Cultural Studies, University Quality-oriented Education and the relationship between teachers and students, Research on University Quality-oriented Education and community evaluation, Research on ways to promote Quality-oriented education in Universities(see Table I).In order to analyze the innovative ideas and research prospects of this topic.

TABLE I LIST OF 1995-2017 QUALITY-ORIENTED EDUCATION RESEARCH TOPIC

\begin{tabular}{|c|c|c|c|}
\hline Subject & time & range & quantity \\
\hline Research on the connotation of Quality-oriented education in Universities & \multirow{8}{*}{$\begin{array}{l}1995- \\
2017\end{array}$} & \multirow{8}{*}{$\begin{array}{l}\text { National core periodicals of China, } \\
\text { CSSCI }\end{array}$} & \multirow{8}{*}{277} \\
\hline Study on the responsibility of University Quality-oriented Education & & & \\
\hline $\begin{array}{l}\text { Research on the relationship between Quality-oriented education and } \\
\text { general education in Universities }\end{array}$ & & & \\
\hline $\begin{array}{c}\text { Research on University Quality-oriented Education and educational } \\
\text { reform }\end{array}$ & & & \\
\hline University Quality-oriented Education and Cultural Studies & & & \\
\hline $\begin{array}{l}\text { University Quality-oriented Education and the relationship between } \\
\text { teachers and students }\end{array}$ & & & \\
\hline $\begin{array}{c}\text { Research on University Quality-oriented Education and community } \\
\text { evaluation }\end{array}$ & & & \\
\hline Research on ways to promote Quality-oriented education in Universities & & & \\
\hline
\end{tabular}

Fund Project: Shandong social science planning research project (15CJYJ11).

Research project of education and teaching reform in

Shandong (2015632)

Supported by scientific research team of Shandong Xiehe University. 


\section{RESEARCH ON THE CONNOTATION AND THE RESPONSIBILITY OF QUALITY-ORIENTED EDUCATION IN UNIVERSITIES}

\section{A. Research on the connotation of Quality-oriented education in Universities}

Study on the connotation of college Quality-oriented education, many scholars have conducted in-depth study, some scholars interpreted from the core of university Qualityoriented education, some scholars from the University Quality-oriented Education composition explained, some scholars analyzed from the characteristics of university Quality-oriented education. Zhang kaizhi believes that the characteristics of university Quality-oriented education can be summed up as follows: internalization, comprehensiveness, harmony, innovation and cultural consciousness [1]. Yang Shuzi puts forward the composition of Quality-oriented education in Universities in China, including the cultivation of moral Quality-oriented, the cultivation of professional Quality-oriented, the cultivation of cultural Quality-oriented, the cultivation of physical and mental qualities, and the cultivation of innovative Quality-oriented [2-4]. Because different students explain the meaning of University Qualityoriented Education from different perspectives, the specific description of the meaning of university Quality-oriented education is not the same, but the views are consistent, and they are not very different.

\section{B. Study on the Responsibility of University Quality-oriented Education}

The research on the responsibility of Quality-oriented education in Colleges and universities mainly focuses on the cultivation of the spirit of academic research, the cultivation of creative talents, and the sustainable development of students. $\mathrm{Xu}$ Jingwu and Bie Dunrong believed that the sustainable development of the students is the ultimate goal of Qualityoriented education, Quality-oriented education in universities to cultivate college students' innovative spirit and practice ability as the key, the talent training mode reform as a breakthrough point, to humanistic Quality-oriented education as the starting point [5].

\section{RESEARCH ON THE RELATIONSHIP BETWEEN QUALITY EDUCATION AND OTHER FACTORS IN UNIVERSITIES}

\section{A. Research on the relationship between Quality-oriented education and general education in Universities}

In the study of the relationship between Quality-oriented education and general education in universities, scholars agree that Quality-oriented education in universities is closely related to general education. Zhang Yaqun believes that the university Quality-oriented education is a special form of general education, and the general education nature of university Quality-oriented education embodies the basic, humanistic and coherent aspects of Education [6]. Zhang Chuting put forward the Quality-oriented education in university is the soul of the general education, general education in Chinese is valued years of Quality-oriented education practice results, general education to Quality-oriented education is more feasible and really, Quality-oriented education to general education more vitality and vigor [7]. Chen Xiangming put forward the concept of general education is a concept in Quality-oriented education above, is a talent training mode, the implementation of the specific content and form of education Quality-oriented education emphasizes education, general education is a kind of talent training mode, improve the Quality-oriented of students is a goal of general education [8].

\section{B. Research on University Quality-oriented Education and educational reform}

With regard to the impact of university Quality-oriented education on educational reform, Pang Haishao put forward the implementation of Quality-oriented education, which initiated three major changes in college education and produced farreaching significance [9].First, the educational concept is shifted from emphasizing the training of specialized personnel to paying more attention to improving the comprehensive quality of students. The two is the great changes in the curriculum system of undergraduate education, general elective course from scratch, improve quality; design of public basic courses are also changing, and the course of quality education play a role. Three, it has initiated the reform experiment of undergraduate education mode of "specialized education on the basis of general education".

The concrete research about the university Quality-oriented education and the education reform mainly includes: the university Quality-oriented education and the curriculum reform research, the university Quality-oriented education and the personnel training pattern research two aspects. The research results of university Quality-oriented education and curriculum reform mainly include the construction of hidden curriculum, the reform of curriculum system and the curriculum guarantee of the practice of university Qualityoriented education. Sun Mingying proposed the hidden curriculum and Quality-oriented education has a fit of inner spirit, value orientation of the construction of hidden curriculum to the concept of Quality-oriented education oriented to cultural connotation of university characteristics; vision and level design approach of hidden curriculum depends on the university leaders and teachers of the hidden curriculum consciousness [10]. Hu Jianhua puts forward the ideas of curriculum reform from the point of view of the relationship between the Quality-oriented of college students and the university curriculum system, such as the overall optimization of curriculum structure, the renewal of curriculum arrangement mode and the renewal of curriculum model [11]. Cai Guochun thinks that the curriculum guarantee of the practice of university Quality-oriented education includes the selection of courses around the target, the improvement of the form and structure of the courses around the target, the improvement of the credit system and the full development of the influence of the latent curriculum [12]. You Ranzhu, the research and reference of American universities comprehensive quality education curriculum in the case of service learning mode, enriches the theory of quality education system in our country, university teachers will promote quality education into daily teaching, quality education from theory to practice and to deepen[13]. 
About University Quality-oriented Education and talent training mode, Li Zhi put forward the mode of evolution through the "four stages theory" of our country's university personnel training: general education mode, the mode of specialist education, the Quality-oriented education oriented model and the integration of general education should be after the Quality-oriented education stage [14]. Zhao Zuobin put forward the successful Quality-oriented education, and provided the train of thought for the new breakthrough of the university education idea and mode [15].

It is not difficult to see from the above research, the scholars from the perspective of talent training mode reform of college Quality-oriented education, has important theoretical and practical significance to promote the implementation of Quality-oriented education, but the existing research on different types of universities in the perspective of Qualityoriented education under the concept of how to reform the personnel training mode of the relative lack of research.

\section{University Quality-oriented Education and Cultural Studies}

With regard to the study of the relationship between university Quality-oriented education and culture, scholars have explored the orientation of traditional culture in university Quality-oriented education and cultural education, which enriched the content of Quality-oriented education research. Wang Enquan puts forward the correct positioning of the role of traditional culture in University Quality-oriented Education from the aspects of carrying forward the Chinese traditional culture, enhancing the national self-confidence of college students, and cultivating their world outlook, outlook on life and values [16]. Zhang Qizhi believes that the implementation of Quality-oriented education in University, need to have accurate knowledge of China excellent traditional culture, the advanced socialist culture as guidance, adhere to the socialist core value system, promote national culture, which is rooted in the minds of teachers and students, which is an important symbol of national prosperity [17]. Zhang Jing think that cultural education as a model of quality education, which is the essence of knowledge in education, through cultural values and other factors are involved, the organic whole culture, cultural education [18].

\section{University Quality-oriented Education and the relationship between teachers and students}

The relationship between teachers and students with education in University, academic research does not see more, Cai Ming presents the characteristics of Quality-oriented education in university teacher-student relationship: both classroom teaching and the extracurricular communication; the coexistence of dominant effect and dominant position; improve the teacher-student relationship depends on the correct understanding of both sides, and to shorten the psychological distance [19]. It provides a new angle of view for Qualityoriented education research.

\section{E. Research on University Quality-oriented Education and university community evaluation}

There is little achievement in the study of the relationship between the Quality-oriented education and the student organizations, and Mao Kaiyi expounds the principles and standards of the evaluation of the college students' community in the perspective of Quality-oriented education. Put forward the evaluation principles for community development goals, different types and grades of the school for the introduction of social forces, development, evaluation; evaluation standard for Quality-oriented of community influence, student participation in three aspects. Advances in Quality-oriented education in universities [20].

\section{RESEARCH ON WAYS TO PROMOTE QUALITY-ORIENTED EDUCATION IN UNIVERSITIES}

The exploration of quality education in Chinese universities started in the early 1980s [21]. In the practice of Qualityoriented education in Colleges and universities, Tsinghua University, Northwestern University, Beijing Institute of Technology, Hainan University, Huazhong University of Science and Technology have achieved certain results. Tsinghua University has experienced constantly enriching and developing process of cognition of "improve the overall Quality-oriented of students" connotation, explores a series of educational reform, including curriculum construction and teaching reform, build a good education environment and strengthening social practice[22].Beijing Institute of Technology has actively explored the construction, theory and practice of "three dimensional, interactive and interactive" university Quality-oriented education system[23].The basic experience of the successful development of cultural Qualityoriented education in Huazhong University of Science and Technology for 10 years is that practice and research are closely integrated, and theory and practice interact and promote each other[21]. Hainan University explored the quality education model of "master of knowledge", "ability training" and "personality molding"[24]. Northwestern University integrates cultural education, scientific research and practical education to realize the trinity of university quality education"[25]. From the existing achievements, it is easy to see that the Quality-oriented education carried out better in Colleges and universities are 985, 211 colleges and universities, and other ordinary colleges and universities have little achievement. Since the concept of Quality-oriented education has been put forward for more than 20 years, the reform and development of Quality-oriented education in China has gone through practice and has gone out of a unique way. It is of great importance to sum up the practice of cultural Qualityoriented education and deepen the theoretical understanding of Quality-oriented education.

\section{CONClusion}

Along with the University of the process of strengthening the promotion of Quality-oriented education, the new period, should be fully out of the theory and practice of Qualityoriented education, promote the comprehensive reform of college education, the necessity of Quality-oriented education in college, some relations characteristics and ways of implementation of Quality-oriented education, to deepen the teaching mode and method of education, construction of continuing education mechanism of science students the Quality-oriented evaluation system and the reform of teachers, 
school management, promote the cleaning system obstacle of Quality-oriented education, the construction of scientific Quality-oriented education system, promote the Qualityoriented education, the real landing.

\section{REFERENCES}

[1] Zhang Kaizhi. Re understanding of University Quality Education [J].China University Teaching, 2011, 12.

[2] Yang Shuzi.The Cultural Quality Education in Universities Facing the 21st Century[J].Journal OF Jiangnan College, 1999,02.

[3] Hao Zhimin, Liu Yucheng, Cong Changfu.On the composition of University Quality Education [J].University Education Science, 2000, 03.

[4] Qu Zhenyuan. Quality-oriented education in Colleges and universities needs real landing [N].GUANGMING RI BAO, 2015, 04, 21.

[5] Xu Jingwu, Bie Dunrong. The new angle of University Quality Education: promoting the sustainable development of College Students [J].University Education Science, 2000, 10.

[6] Zhang Yaqun. Quality education in Universities: a special form of general education $[\mathrm{J}]$. Journal of China University of Geosciences (Social Sciences Edition), 2013, 01.

[7] Zhang Chu-ting. Quality education, the soul of general educationConcurrently discuss the trend of quality education in our universities [J].Journal of Higher Education 2008, 07.

[8] Chen Xiangming. An analysis of some concepts about general education [J].Journal of Higher Education, 2006, 03.

[9] Pang Haishao, Huan Xiuhong. Reforming of University Education Caused by Quality-oriented Education [J]. China Higher Education Research, 2015, 09.

[10] Sun Mingying, Dai Linfu.The construction of hidden curriculum from the perspective of University Quality Education [J]. Modern Education Science, 2011, 03.

[11] Hu Jianhua. University Quality Education and curriculum system reform [J].Jiangsu Higher Education, 1999, 05.

[12] Cai Guochun. On the curriculum guarantee of the practice of quality education in Universities [J].Modern Education Management, 1997, 06.
[13] You Zhuran, Hu Yingzi. Service learning--Research on the curriculum model of University Quality Education [J].Modern education management2011, 11.

[14] Li Zhi, Yang Xingfang. Put forward and open mode of the historical evolution of "four stages theory" -- on "quality education" talent cultivation of University in China [J].Heilongjiang Researches on Higher Education, 2010, 02.

[15] Zhao Zuobin. Successful quality education -- a new breakthrough in the concept and mode of university education [J].China Higher Education Research, 2006, 03.

[16] Wang Enquan. Research on the orientation of traditional culture in University Quality Education [J].Higher Agricultural Education, 2015, 11.

[17] Cai Ming.0n the Handling of the Relationship between Teachers and Students in University Quality-Oriented Education[J].Journal of Jiangsu University(Higher Education Study Edition),2005,10.

[18] From "knowledge education" to "cultural education" -- University Quality Education from the perspective of HolismZhang Jing, He Zujian Higher education research, 2008, 11.

[19] Mao Kaiyi. Principle and Criteria for the Evaluation of College Students' Community from the Perspective of Quality Education [J].Heilongjiang Researches on Higher Education, 2017, 05.

[20] Li Shuqin Cai Wenpeng. Exploration and Practice of Quality-oriented Education in Tsinghua University $(1983-1993)$ [J].China Higher Education Research, 2015, 04.

[21] Guo Dacheng \& Sun Gangcheng. The Spirit of University Is the Soul of Quality Education in University [J].Educational Research, 2013, 10.

[22] LIU Xianjun. Researching on the theory and the practice and achieving the promotion from each other-Review on ten years' quality education of HUST [J].Journal of Higher Education, 2005, 03.

[23] Tan Bing. On the Mode of Quality Education for Postgraduates:

[24] An Integrative Scheme of "Know ledge Instruction, Ability Cultivation and PersonalityM olding" [J].Journal of Hainan Normaluniversity (SocialSciences), 2007, 01.

[25] Li Hao, Cao Mingming, LiJianli, Zhou Chao, Ni Xiaoyong. The trinity of quality education in universities"[J].China University Teaching, 2014, 07. 